\title{
Dental Pathology, Wear, and Diet in a Hunting and Gathering Forest-Dwelling Group: The Batak People of Palawan Island, The Philippines
}

\author{
Christy G. Turner II* and James F. Eder \\ School of Human Evolution and Social Change, Arizona State University, Tempe, AZ
}

\begin{abstract}
Described are observations on Batak foods, tooth use, oral hygiene, and resulting wear and oral pathology in dental casts of 29 Batak ranging from 15 to 49 years of age. Commonly consumed foods are roughly 80 percent plant, and 20 percent animal products. Cooking is common. Eating includes one or two main daily meals with occasional snacking. Cariogenic commerciallymanufactured flour and sugar are rarely available.
\end{abstract}

Most of human prehistory saw our ancestors living in small groups as opportunistic hunters and gatherers. Studies of pre-agricultural teeth have repeatedly shown that diet and tooth use behaviors were abrasive, tough, and destructive, producing much tooth wear, periodontal disease, alveolar abscessing, and tooth chipping and fracturing. On the other hand, hunter-gatherers were largely free of both occlusal and interproximal caries and other disorders linked to cariogenic diets. Despite archaeologically-derived pre- and early agricultural human teeth having been described many times around the world, there are very few accounts in the dental anthropological literature that include ethnographic observations of actual diet and tooth-use behaviors coupled with descriptions of the related oral pathologies and wear. This is especially so for remnant living groups whose consumption of refined sugar and flour is limited. The best known of such ethno-dentally described populations with minimal modern contact and exchange are the Australian Aborigines studied by T. D. Campbell (1925, 1939) and the East Greenland Eskimo researched by P. O. Pedersen (1938) . Both workers were trained as dentists, which explains their interest in diet, toothuse, and oral pathology. Ethnologists, on the other hand, almost always describe diet and food preparation techniques, but seldom comment on the resultant oral conditions. Bioarchaeologists with paleo-ethnographic and dental interests describe oral health but generally lack the means to do more than infer diet based on archaeologically-recovered foodstuffs and artifacts
Oral hygiene involves "finger-brushing" of anterior teeth with fine sand. The practice is more common in females than in males. Caries are rare in both sexes as is antemortem tooth loss. Tooth chipping is more common in males. Periodontal disease is generally slight and nearly equal in the sexes. Tooth wear is relatively slight but strongly age-related as in many other populations. Dental Anthropology 2006;19(1):15-22.

involved in food-preparation. Such artifacts include grinding stones, cooking vessels, butchered bones, and similar materials. Rarely, human coprolites are recovered in archaeological excavations. These metabolic residues are inherently rich in dietary information.

While the strength of bioarchaeological inference about diet and tooth-use behavior can be quite substantial, it is always desirable to have actual observations when dealing with uniformitarian cause and effect relationships, which in this case are diet, tooth use, and oral health. Hence, this brief report identifies some of the foods and toothuse behaviors of the Batak observed by ethnologist and co-author JFE, and the resultant effects on the dentition identified by bioarchaeologist CGT. Information concerning the origin and affinity of the Batak based on the dental morphology of the sample described herein can be found in Turner and Eder (2005). We hope this note will stimulate further dental anthropological study in the few remaining hunter-gatherer groups around the world.

The Batak are one of approximately twenty ethnolinguistically-distinct groups of so-called "Negrito" peoples inhabiting various hinterland regions of the Philippines. Like other Filipinos, they today speak languages of the Austronesian language family,

*Correspondence to: Christy G. Turner II. School of Human Evolution and Social Change, Arizona State University, Tempe, AZ 85287-2404

E-mail: chrstygturner@aol.com 
and they share many cultural beliefs and practices with neighboring farming peoples. But Philippine Negritos stand out by virtue of their mobile forest foraging life way and the bundle of physical attributes - short stature, dark skin, and curly hair - that earned these distinctive-looking peoples their name (Eder, 1987).

The Batak themselves inhabit a series of eight river valleys lying along the east coast of the north central part of Palawan Island, in the southwestern corner of the Philippine archipelago. Their subsistence economy today combines hunting and gathering, collection and sale of commercially valuable forest products, shifting cultivation, and wage labor for outsiders. Wild yams and wild honey once provided the bulk of the carbohydrates in the Batak diet. Today, rice, corn, sweet potato, cassava, and plantain are also important starch sources. Some brown sugar is used, but in small quantities and almost exclusively to sweeten coffee. Protein sources include wild pig, gliding squirrels, porcupines, wild chickens, and other forest animals, and fish, eels, mollusks and crustaceans obtained from rivers and streams. Bamboo shoots, rattan pith, and a variety of wild nuts, fruits, and greens are also consumed (Eder, 1987).
Most food is roasted in wood fires or cooked (typically by boiling) in cast iron cooking vessels. Typically there are two meals a day, one at noon and one in the evening, but sometimes there is only one. There is often considerable snacking in the course of the day, as foods are encountered on the trail or brought into camp. The contemporary diet is low in animal protein, low in vegetables, and probably even low in calories. Actual food consumption patterns can be narrow and monotonous for extended periods of time. Drinking water is obtained from springs and streams. Teeth are cleaned with toothpicks and finger-brushed with fine sand or (sometimes) with toothbrushes. Betel nut chewing is common, and all adult teeth are stained accordingly.

\section{MATERIALS AND METHODS}

Eder and helpers collected dental impressions of 29 Batak natives whose ages ranged from 15 to about 49 years. The sample size was limited by the amount of impression powder (Jeltrate ${ }^{\circledR}$ ) and plaster that could be conveniently carried into the field along with other more critical supplies. Positive plaster casts were poured immediately after the impressions were made.

\begin{tabular}{|l|l|l|l|l|l|l|l|l|l|l|l|l|l|l|l|l|l|l|l|l|}
\hline & 0.5 & 0.6 & 0.7 & 0.8 & 0.9 & 1.0 & 1.1 & 1.2 & 1.3 & 1.4 & 1.5 & 1.6 & 1.7 & 1.8 & 1.9 & 2.0 & 2.1 & 2.2 & 2.3 & 2.4 \\
\hline 14 & & & & & & & & & & & & & & & & & & & & \\
\hline 16 & F & F & F & & & & & & & & & & & & & & & & & \\
\hline 18 & $\mathrm{M}$ & $\mathrm{F}$ & & & & & & & & & & & & & & & & & & \\
\hline 20 & & F & F & & & & & & & & & & & & & & & & & \\
\hline 22 & & F & F & F & & & & & & & & & & & & & & & & \\
\hline 24 & & & & F & & & & & & & & & & & & & & & & \\
\hline 26 & & & M & & M & & & & & & & & & & & & & & & \\
\hline 28 & & & $\mathrm{M}$ & $\mathrm{F}$ & $\mathrm{M}$ & $\mathrm{M}$ & & & & & & & & & & & & & & \\
\hline 30 & & & & $\mathrm{~F}$ & & & & $\mathrm{~F}$ & & $\mathrm{M}$ & & & & & & & & & & \\
\hline 32 & & & & & & & & & & & & & & & & & & & & \\
\hline 34 & & & & & & & & & & & & & & & & & & & & \\
\hline 36 & & & & & & & & & & $\mathrm{M}$ & & & & & & & & & & \\
\hline 38 & & & & & & & & & & & & & & & & & & & & \\
\hline 40 & & & & & & & & & & & & & & & & & & & & \\
\hline 42 & & & & & & & & & & & & & & & & & & & & \\
\hline 44 & & & & & & & & & & & & & & & & & & & & \\
\hline 46 & & & & & & & $\mathrm{M}$ & & $\mathrm{M}$ & $\mathrm{F}$ & & & & & $\mathrm{M}$ & & & & & \\
\hline 48 & & & & & & & & & & & & & & & & & & & \\
\hline 50 & & & & & & & & & & & & & & & & & & & F \\
\hline
\end{tabular}

Fig. 1. Distribution between the average wear (horizontal axis) and the person's age (vertical axis) for maxillary teeth. Average wear was based on the 5 -grade ordinal scheme: $0=$ no wear, $1=$ dentine exposed, $2=$ cusps worn off, 3 = pulp exposed, $4=$ root stump functional (Turner, Nichol and Scott, 1991). The correlation coefficient between age and mean wear for Batak male maxillary teeth is $r=0.749$; for Batak females, $r=0.894$. Sex of the specimen is coded as male (M) or females (F). 


\begin{tabular}{|l|l|l|l|l|l|l|l|l|l|l|l|l|l|l|l|l|l|l|l|l|}
\hline & 0.5 & 0.6 & 0.7 & 0.8 & 0.9 & 1.0 & 1.1 & 1.2 & 1.3 & 1.4 & 1.5 & 1.6 & 1.7 & 1.8 & 1.9 & 2.0 & 2.1 & 2.2 & 2.3 & 2.4 \\
\hline 14 & & & & & & & & & & & & & & & & & & & & \\
\hline 16 & $\mathrm{~F}$ & $\mathrm{~F}$ & $\mathrm{~F}$ & & & & & & & & & & & & & & & & & \\
\hline 18 & & & $\mathrm{~F}$ & & & & & & & & & & & & & & & & & \\
\hline 20 & & $\mathrm{M}$ & & $\mathrm{F}$ & & & & & & & & & & & & & & & & \\
\hline 22 & & & $\mathrm{~F}$ & $\mathrm{~F}$ & & & & & & & & & & & & & & & & \\
\hline 24 & & & $\mathrm{~F}$ & $\mathrm{~F}$ & $\mathrm{~F}$ & & & & & & & & & & & & & & & \\
\hline 26 & & & $\mathrm{M}$ & & $\mathrm{F}$ & & & & & & & & & & & & & & & \\
\hline 28 & & & $\mathrm{M}$ & $\mathrm{F}$ & $\mathrm{M}$ & & & & & & & & & & & & & & & \\
\hline 30 & & & $\mathrm{M}$ & & & $\mathrm{M}$ & & & & & & & & & & & & & & \\
\hline 32 & & & & $\mathrm{~F}$ & & $\mathrm{~F}$ & $\mathrm{M}$ & & & & & & & & & & & & & \\
\hline 34 & & & & & & & & & & & & & & & & & & & & \\
\hline 36 & & & & & & & $\mathrm{M}$ & & & & & & & & & & & & & \\
\hline 38 & & & & & & & & & & & & & & & & & & & & \\
\hline 40 & & & & & & & & & & & & & & & & & & & & \\
\hline 42 & & & & & & & & & & & & & & & & & & & & \\
\hline 44 & & & & & & & & & & & & & & & & & & & & \\
\hline 46 & & & & & & & & & & & $\mathrm{~F}$ & & & & & & $\mathrm{M}$ & & & \\
\hline 48 & & & & & & & & & & & $\mathrm{M}$ & & $\mathrm{M}$ & & & & & & \\
\hline 50 & & & & & & & $\mathrm{~F}$ & & & & & & & & & & & & \\
\hline
\end{tabular}

Fig. 2. Distribution between the average wear (horizontal axis) and the person's age (vertical axis) for mandibular teeth. Average wear was based on the 5 -grade ordinal scheme: $0=$ no wear, $1=$ dentine exposed, $2=$ cusps worn off, 3 = pulp exposed, 4 = root stump functional (Turner, Nichol and Scott, 1991). The correlation between age and mean wear for Batak male maxillary teeth was $r=0.749$; for Batak females, $r=0.894$. Sex of the specimen is coded as male $(\mathrm{M})$ or female $(\mathrm{F})$.

Descriptions of the dental conditions are based on standards used in the Arizona State University Dental Anthropology System (ASU DAS) (Turner, Nichol and Scott, 1991).

\section{RESULTS}

\section{Wear}

Tooth wear was scored for all observable occlusal surfaces. The mean scores for each of the studied Batak males and females is given in Tables 1 and 2. As is evident, tooth wear is strongly related to age, i.e. mean wear, which was calculated by summing the wear scores for each tooth in an individual and dividing by the number of teeth that the individual possessed. For example, male number 3 in Table 1, age 19, had a total maxillary wear score of 9.0, which divided by his 16 teeth gives a mean wear score of 0.56 . In contrast, the 47 year old male number 7 has a mean maxillary wear score of 1.10. This is almost exactly twice that of Batak number 3 .

The relationship between age and mean wear is plotted in Figures 1 and 2. The age-mean wear relationship is quite evident, that is, strongly positive. The correlation coefficients for upper male age-mean dental wear is $r=0.749$; for female upper teeth $r$ $=0.894$. For the lower jaws, male $r=0.860$; female $r$ $=0.866$. These values suggest that the tooth wear scores provided here could serve as a useful guide for estimating age in prehistoric hunter-gatherers who lived in habitats similar to that of the Batak.

A relationship between tooth wear and caries in these hunter-gatherers can also be seen. In Tables 1 and 2, some of the males and females with one or more carious teeth have mean wear scores somewhat less than non-carious individuals of comparable age. One interpretation of this relationship is that individuals with caries do not chew as much or as heavily as do caries-free individuals. Obviously, the relationship between caries and tooth wear would have some effect on how much one can rely on wear to aid in estimating age of prehistoric human remains. Although interproximal caries could not be looked for in our dental casts, we assume that there were some, and that they also contributed to lowered use of the jaws due to pain and discomfort. 
TABLE 1. Batak maxillary dental wear

\begin{tabular}{|c|c|c|c|c|c|}
\hline $\begin{array}{l}\text { Individual } \\
\text { Number }\end{array}$ & Age & $\begin{array}{l}\text { Total } \\
\text { Wear }\end{array}$ & $\begin{array}{l}\text { Number } \\
\text { of Teeth }\end{array}$ & $\begin{array}{l}\text { Mean } \\
\text { Wear }\end{array}$ & Caries \\
\hline \multicolumn{6}{|c|}{ Male Maxilla } \\
\hline 3 & 19 & 9.0 & 16 & 0.56 & \\
\hline 27 & 26 & 12.0 & 16 & 0.75 & \\
\hline 1 & 28 & 13.0 & 16 & 0.81 & \\
\hline 21 & 28 & 14.0 & 16 & 0.87 & \\
\hline 20 & 29 & 12.0 & 16 & 0.75 & RM1 \\
\hline 23 & 29 & 17.0 & 16 & 1.06 & \\
\hline 11 & 31 & 22.0 & 16 & 1.37 & \\
\hline 10 & 36 & 21.5 & 15 & 1.43 & \\
\hline 5 & 45 & 26.5 & 13 & 2.04 & \\
\hline 22 & $>45$ & 31.5 & 14 & 2.25 & \\
\hline 7 & 47 & 16.5 & 15 & 1.10 & LP1 \\
\hline $13^{\mathrm{a}}$ & Adult & 15.5 & 12 & 1.29 & \\
\hline \multicolumn{6}{|c|}{ Female Maxilla } \\
\hline 2 & 15 & 8.0 & 16 & 0.50 & \\
\hline 9 & 15 & 10.5 & 14 & 0.75 & RM1 \\
\hline 26 & 15 & 8.0 & 14 & 0.57 & \\
\hline 28 & 18 & 7.0 & 14 & 0.50 & \\
\hline 8 & 20 & 10.0 & 16 & 0.62 & RM1 \\
\hline 4 & 21 & 11.0 & 16 & 0.69 & \\
\hline 25 & 22 & 9.0 & 16 & 0.56 & \\
\hline 24 & 22 & 11.5 & 15 & 0.77 & \\
\hline 14 & 23 & 13.0 & 14 & 0.93 & \\
\hline 17 & 23 & 12.0 & 16 & 0.75 & LM3 \\
\hline 18 & 24 & 12.5 & 16 & 0.78 & \\
\hline 12 & 26 & 15.0 & 16 & 0.94 & \\
\hline 16 & $\sim 28$ & 13.0 & 16 & 0.81 & \\
\hline 29 & 30 & 19.5 & 16 & 1.22 & \\
\hline 19 & 30 & 12.5 & 16 & 0.78 & \\
\hline 6 & 46 & 23.0 & 16 & 1.44 & \\
\hline 15 & $\sim 49$ & 36.0 & 15 & 2.40 & LRM1 \\
\hline
\end{tabular}

${ }^{a}$ Man had congenital absence of four upper teeth (LRI2, RC, LM3) and three lower teeth (RI1, LRM3). See Figs. 7 and 8.

Table 3 provides the frequencies of crown caries, antemortem tooth loss, crown chipping, periodontal disease, and oral hygiene. Inasmuch as these observations were made from plaster casts, the values probably err slightly on the side of under-reporting; for example, caries and toothpick grooves could not be looked for on interproximal crown surfaces including those of the roots. The extent of general bone loss from periodontal disease, which is easily studied in skeletal remains, is largely hidden by gum tissue in the living.

\section{Caries}

The number of Batak with one or more crown caries $(31.0 \%)$ is unexceptional for a hunting and gathering population, although it is at the upper end of the range. Among the Middle to Late Period (ca. 1,000 B.C.) Jomonese of central Japan (a hunting, fishing, gathering, and possibly small scale horticultural population), the percentage of individuals with one or more caries was $42.7 \%$ (Turner, 1979). The frequency of Batak carious teeth (2.1\%), mostly molars, is well in line with prehistoric hunting and gathering economies around the world. Within the Batak sample, there is no statistically significant difference between males and females for caries.

\section{Antemortem loss}

The low amount of antemortem tooth loss is consistent with the low frequency of caries-caries being viewed as the major cause of antemortem loss, 


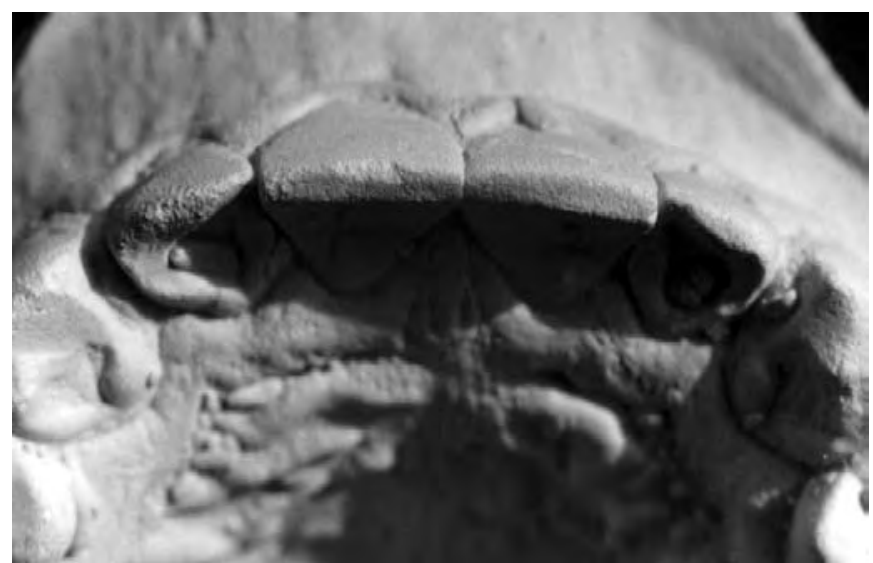

Fig. 3. Labial surface smoothing of upper left and right central and lateral incisors. The cast (number 3) was from a young Batak adult male, age 19 years (CGT neg. 3-22-02:27).

especially for molars, which is the situation in this sample. Two lost incisors occurred in males. Trauma likely was the cause of the loss. Combining antemortem loss and carious teeth, only $3.0 \%$ of all teeth have one or both of these conditions. This is far less than what occurs in agricultural populations with their highly processed, sticky, and cariogenic cereal-based foodstuffs.

\section{Chipping}

Occlusal surfaces of an individual's teeth may exhibit one or more nicked or chipped edges. Chipped areas are usually less than $0.5 \mathrm{~mm}$ in diameter (Figs. 5 and 8). Chipping is attributable to various activities ranging from the heavy use of teeth as vice-like tools, breaking up of hard materials like starvation-driven scavenging of bone, gritty mineral food contaminants, to accidental trauma arising from falls, and other

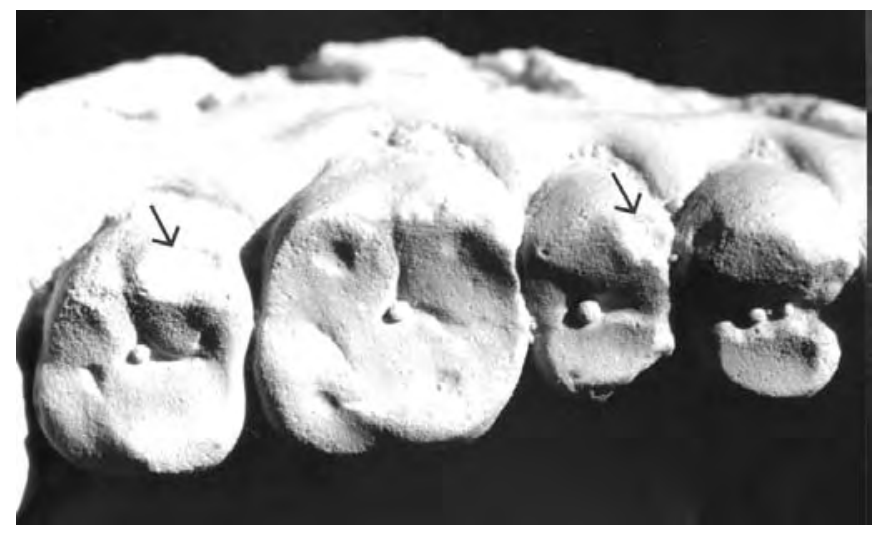

Fig. 5. Arrows point to occlusal chipping of cast number 21, an adult Batak male, age 28 years (CGT neg. 3-22-02:20).

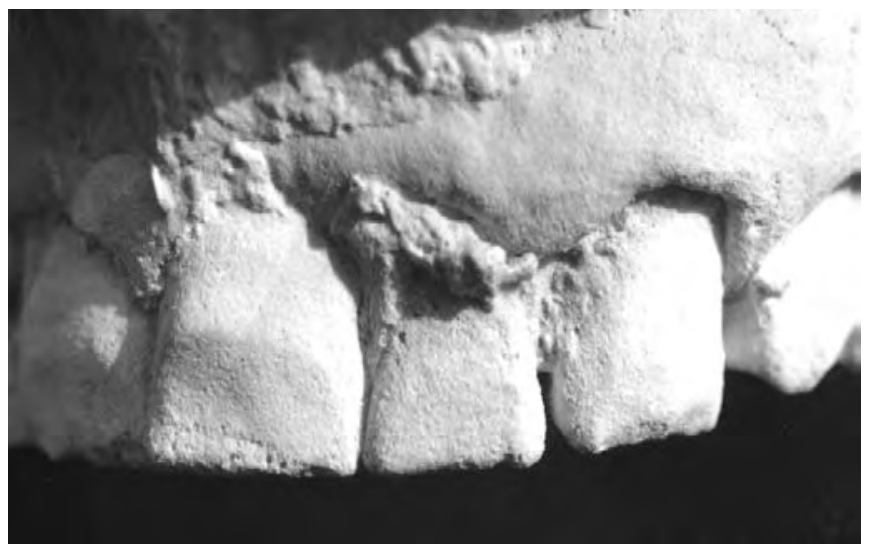

Fig. 4. Labial surface smoothing of cast number 7 upper central incisors, an adult Batak male, age about 47 years. Periodontal disease was judged to be "medium" (CGT neg. 3-22-02:24).

sources. Both individual and tooth counts show that the Batak males have significantly more chipping than do the females. Almost all males have one or more chipped teeth $(91.7 \%)$ in contrast to females $(35.3 \%)$ who have only about one third of their number exhibiting chipping. Pooled, the number of chipped teeth occur more often in the back of mouth (chipped incisors, 9; canines, 3; premolars, 21, molars, 26), suggesting dietary and tooth use activities as the major contributor to Batak chipping rather than trauma. Eder notes that chipping was not likely caused by fighting since males never fight among themselves. There is nothing in these values to suggest excessive inter-sex conflict where one would expect either comparable overall female tooth chipping (females being abused and hit; male chipping due to heavy tooth use), or excessive anterior tooth chipping (falls by children, adolescent hitting, being shoved, etc.). Eder feels that the observed pattern

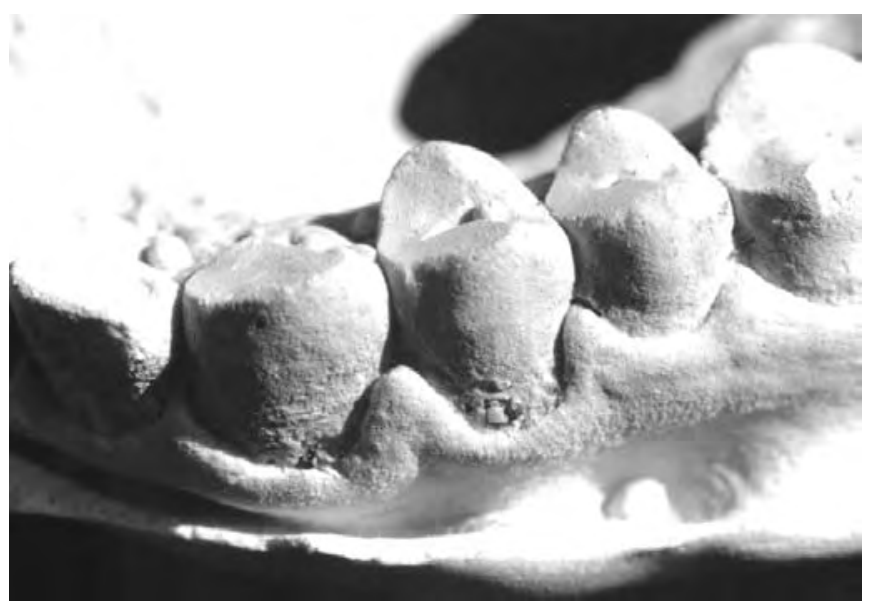

Fig. 6. Periodontal disease of cast number 14, an adult Batak female, age 23 years. Disease grade judged to be "slight" (CGT neg. 3-22-02:22). 
TABLE 2. Batak mandibular dental wear

\begin{tabular}{|c|c|c|c|c|c|}
\hline $\begin{array}{l}\text { Individual } \\
\text { Number }\end{array}$ & Age & $\begin{array}{l}\text { Total } \\
\text { Wear }\end{array}$ & $\begin{array}{l}\text { Number } \\
\text { of Teeth }\end{array}$ & $\begin{array}{l}\text { Mean } \\
\text { Wear }\end{array}$ & Caries \\
\hline \multicolumn{6}{|c|}{ Male Maxilla } \\
\hline 3 & 19 & 9.0 & 16 & 0.56 & \\
\hline 27 & 26 & 11.0 & 16 & 0.69 & \\
\hline 1 & 28 & 12.0 & 16 & 0.75 & \\
\hline 21 & 28 & 14.0 & 16 & 0.87 & \\
\hline 20 & 29 & 10.5 & 16 & 0.66 & \\
\hline 23 & 29 & 17.0 & 16 & 1.06 & \\
\hline 11 & 31 & 18.0 & 16 & 1.12 & \\
\hline 10 & 36 & 17.5 & 16 & 1.09 & LRM2, M3 \\
\hline 5 & 45 & 25.0 & 12 & 2.08 & \\
\hline 22 & $>45$ & 27.0 & 16 & 1.69 & RM2 \\
\hline 7 & 47 & 19.5 & 16 & 1.22 & \\
\hline 13 & Adult & 20.0 & 13 & 1.54 & \\
\hline \multicolumn{6}{|c|}{ Female Maxilla } \\
\hline 2 & 15 & 8.0 & 16 & 0.50 & \\
\hline 9 & 15 & 8.0 & 14 & 0.57 & LM1 \\
\hline 26 & 15 & 9.5 & 14 & 0.68 & \\
\hline 28 & 18 & 10.0 & 14 & 0.71 & \\
\hline 8 & 20 & 12.5 & 16 & 0.78 & \\
\hline 4 & 21 & 12.0 & 16 & 0.75 & \\
\hline 25 & 22 & 11.5 & 15 & 0.77 & \\
\hline 24 & 22 & 12.5 & 16 & 0.78 & \\
\hline 14 & 23 & 11.0 & 14 & 0.79 & \\
\hline 17 & 23 & 14.5 & 16 & 0.91 & \\
\hline 18 & 24 & 12.5 & 16 & 0.78 & \\
\hline 12 & 26 & 15.0 & 16 & 0.94 & \\
\hline 16 & $\sim 28$ & 13.5 & 15 & 0.90 & RM1,2; LRM3 \\
\hline 29 & 30 & 15.5 & 16 & 0.97 & \\
\hline 19 & 30 & 12.0 & 16 & 0.75 & \\
\hline 6 & 46 & 24.0 & 16 & 1.50 & \\
\hline 15 & $\sim 49$ & 14.0 & 13 & 1.08 & LM2 \\
\hline
\end{tabular}

almost certainly relates to a disproportionate tendency for men more than women to put non-food items in their mouths in the course of producing artifacts, or ad hoc tools. Despite the sexes basically eating the same foods, he has seen Batak men more often than women biting on lengths of rattan, and using their teeth to crack open nuts, break bones to obtain the marrow, and even chewing on turtle carapaces. After such sorts of tooth use to access nutrients, the man would share with his wife or others.

\section{Periodontal disease}

While nearly all of the 29 Batak exhibit some degree of gingival border recession, detachment, and swelling, indicating bacterial infection and inflammation, we characterize the amount as having been mostly slight in both sexes (Fig. 6). There is, as expected, a small degree of age-related expression of periodontal disease, but the relationship is weak. Periodontal disease among the Batak sample seems more idiosyncratic than systematic. Thus, the Batak oral activities, while culturally and environmentally channeled, have also a degree of individual determination. This can include regularity of oral hygiene practiced, immune strength, amount of fibrous and other foods consumed that have the inherent capability to remove plaque, and other such variables, including choices of foods that might possess antibacterial or anti-inflammatory qualities.

\section{Oral hygiene}

The type of oral hygiene that can be detected from our Batak dental casts includes an interesting flattening of the labial surface of one or more upper incisors and canines (Figs. 3 and 4). As Eder observed, 
TABLE 3. Batak oral health

\begin{tabular}{|c|c|c|c|c|c|c|c|}
\hline \multirow[b]{2}{*}{ Condition } & \multicolumn{2}{|c|}{ Male } & \multicolumn{2}{|c|}{ Female } & \multirow{2}{*}{$\begin{array}{l}\text { M \& F X } \\
\text { P-value }\end{array}$} & \multirow[b]{2}{*}{$\mathrm{n}$} & \multirow{2}{*}{$\begin{array}{l}\text { Total } \\
\text { Percent }\end{array}$} \\
\hline & $\mathrm{n}$ & Percent & $\mathrm{n}$ & Percent & & & \\
\hline Individuals, 1 or more caries & 4 & 33.3 & 5 & 29.4 & n.s. $(>0.80)$ & 9 & 31.0 \\
\hline Individuals, no caries & 8 & 66.7 & 12 & 70.6 & & 20 & 69.0 \\
\hline Carious incisors, $\mathrm{n}=227$ & 0 & 0 & 0 & & & & \\
\hline Carious canines, $\mathrm{n}=115$ & 0 & 0 & 0 & & & & \\
\hline Carious premolars $n=232$ & 1 & 0 & 1 & & & & \\
\hline Carious molars $\mathrm{n}=315$ & 6 & 11 & 17 & & & & \\
\hline Carious teeth $n=889$ & 7 & 11 & & & n.s. $(>0.80)$ & 18 & 2.1 \\
\hline Antemortem loss, incisors & 2 & 0 & 2 & & & & \\
\hline Antemortem loss, canines & 0 & 0 & 0 & & & & \\
\hline Antemortem loss, premolars & 0 & 0 & 0 & & & & \\
\hline Antemortem loss, molars & 3 & 4 & 7 & & & & \\
\hline Caries \& antemortem loss, n = 898 & 12 & 3.3 & 15 & 2.9 & & 27 & 3.0 \\
\hline Individuals, chipping, $\mathrm{n}=29$ & 11 & 91.7 & 6 & 35.3 & sig. $(<0.01)$ & 17 & 58.6 \\
\hline $\begin{array}{l}\text { Teeth, chipping, } \mathrm{n}=887 \\
\quad(\mathrm{male}=366 ; \text { female }=521)\end{array}$ & 37 & 10.1 & 14 & 2.7 & sig. $(<0.01)$ & 51 & 5.7 \\
\hline \multicolumn{8}{|l|}{ Periodontal disease, individuals } \\
\hline Absent & 0 & 0.0 & 4 & 25.0 & & 4 & 13.8 \\
\hline Slight & 8 & 66.7 & 10 & 62.5 & & 18 & 62.1 \\
\hline Medium & 3 & 25.0 & 1 & 6.2 & & 4 & 13.8 \\
\hline Severe & 1 & 8.3 & 1 & 8.3 & & 2 & 6.9 \\
\hline Total & 28 & 96.5 & & & & & \\
\hline Upper labial flattening, inds. & 6 & 54.5 & 15 & 88.2 & sig. $(<0.01)$ & 21 & 75.0 \\
\hline Lower labial flattening, inds. & 0 & 0.0 & 0 & 0.0 & & 0 & 0.0 \\
\hline Central incisors, flattened & 10 & 50.0 & 34 & 88.2 & sig. $(<0.01)$ & 54 & 81.5 \\
\hline Lateral incisors, flattened & 6 & 30.0 & 20 & 58.8 & sig. $(<0.05)$ & 54 & 48.1 \\
\hline Canines, flattened & 3 & 14.3 & 14 & 41.2 & sig. $(<0.05)$ & 55 & 30.9 \\
\hline
\end{tabular}

this labial flattening results from the abrasive action of finger-brushing using fine sand or silt in water. There are significantly more females $(88.2 \%)$ with labial-abrasion than males $(54.5 \%)$. This holds also for the actual number of abraded teeth (Table 3). The absence of abraded lower anterior teeth is interesting from a cosmetic standpoint, as it is primarily the upper anterior teeth that are apparent during smiling or other teeth-displaying behavior.

\section{Congenital absence}

Figures 7 and 8 show upper and lower dental casts of a Batak male who likely had seven congenitally missing teeth. While congenital absence is not normally considered as an oral pathology, we nevertheless include the illustrations to indicate some manner of developmental disturbance that might have had a link to fixed or unfixed external environmental factors, even possibly involving the degree of group inbreeding or population genetic bottle-necking sometime in the past. In any event, congenital absence is a category of dental variation that often gets left out of both morphological and pathological characterizations of human populations.

\section{DISCUSSION}

As hunting and gathering disappears as an economic way of human life, the opportunity to observe the ethnography of dentally related activities and diet, and to match these observations with the resultant effects on teeth, is drawing to a close. In fact, very few ethnographic observations on tooth use and 


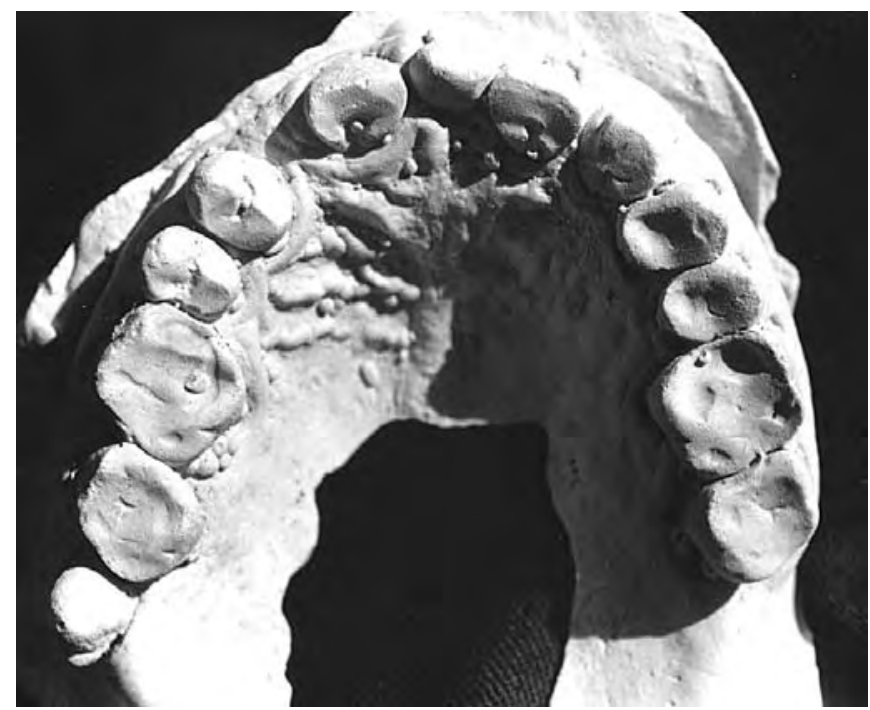

Fig. 7. Absence of four maxillary teeth of cast number 13, a Batak male, age about 34 years. Presumably congenitally missing are the right lateral incisor and canine, the left lateral incisor, and the left third molar. The right third molar is peg-shaped with a lingualbuccal diameter of $6.5 \mathrm{~mm}$. There is a cone-shaped supernumerary tooth between the central incisors (CGT neg. 3-22-02:15).

diet, coupled with oral pathology examinations, can be found in the dental anthropological literature. Those that are best known were made by dentists, seldom anthropologists. Hence, this brief report represents a contribution to an uncommon line of investigation of human tooth use and its results. Our sample comes from a remnant forest-dwelling hunting and gathering group living in the Philippines, the Batak. The results of our pathology examination (wear, caries, antemortem loss, chipping, periodontal disease, oral hygiene) of living Batak people are nicely in line with other dental studies of prehistoric hunting and gathering people throughout the world. The dentally destructive diet associated with cariogenic agricultural foodstuffs and processing is not evident in the Batak sample. What stands out as markedly different is the effect of oral hygiene on the Batak upper anterior teeth, the observed actual activities demonstrably producing the labial flattening of the upper anterior teeth. This flattening would normally have been considered as intentional modification had the acts of teeth cleansing not been observed by the ethnographer (JFE). Also, the probable cause of tooth chipping has been identified as a result of ethnographic observation.

\section{ACKNOWLEDGMENTS}

The dental impressions were collected with the assistance of Rafaelita Fernandez and Raul Fernandez,

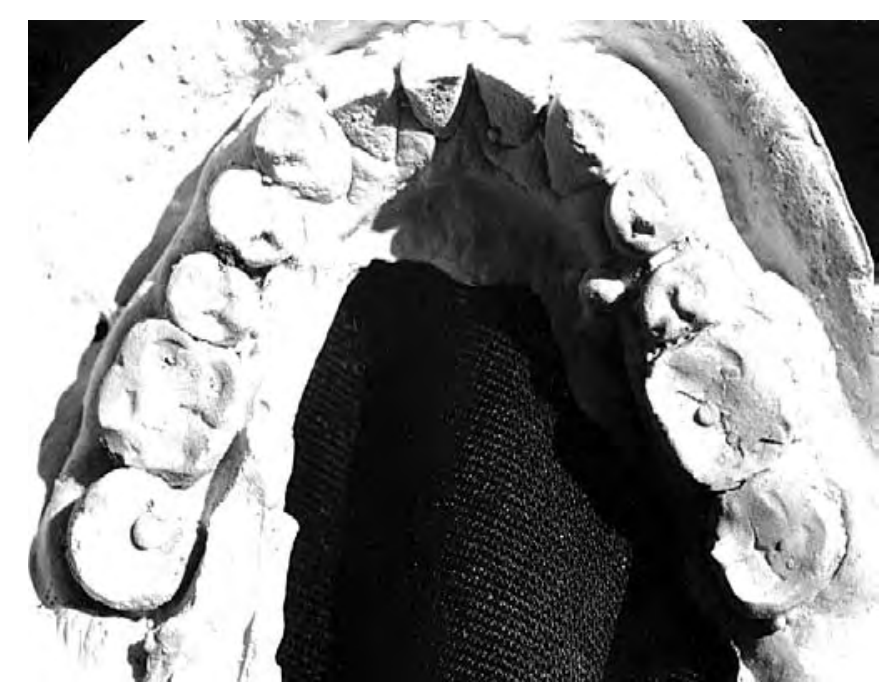

Fig. 8. Absence of three mandibular teeth of cast number 13 (Fig. 7). Missing are the right central incisor, and both third molars. Cusp 2 of the right second molar is chipped (CGT neg. 3-22-02:17).

from the Batak inhabiting the Langogan River valley of central Palawan Island.

\section{LITERATURE CITED}

Campbell TD. 1925. Dentition and palate of the Australian Aboriginal. Adelaide: University of Adelaide Publications, Keith Sheridan Foundation No. 1.

Campbell TD. 1939. Food, food values and food habits of the Australian Aboriginals in relation to their dental conditions. Aust J Dent 43:1-15.

Eder JF. 1987. On the road to tribal extinction: depopulation, deculturation, and adaptive wellbeing among the Batak of the Philippines. Berkeley: University of California Press.

Pedersen PO. 1938. Investigations into dental conditions of about 3,000 ancient and modern Greenlanders. Dental Record 58:191-198.

Turner CG II, Eder JF. 2005. Dentition of the Batak people of Palawan Island, the Philippines: Southeast Asian Negrito origins. In: Oxenham M, Tayles N, editors. Bioarchaeology of Southeast Asia. Cambridge: University of Cambridge Press, p 172-187.

Turner CG II, Nichol CR, Scott GR. 1991. Scoring procedures for key morphological traits of the permanent dentition. In: Kelley MA, Larsen CS, editors. Advances in dental anthropology. New York: Wiley Liss, p 13-31. 